\title{
De la moral del sacrificio a la conciencia de la precariedad Un análisis cualitativo de los discursos sobre la evolución de la crisis en España ${ }^{1}$
}

\author{
Luis Enrique Alonso \\ Universidad Autónoma de Madrid \\ luis.alonso@uam.es
Carlos Jesús Fernández Rodríguez
Universidad Autónoma de Madrid carlos.fernandez@uam.es \\ Rafael IBÁÑEz RoJo \\ Universidad Autónoma de Madrid \\ rafael.ibanez@uam.es
}

Recibido: 09-06-2015

Aceptado: 08-02-2016

\section{Resumen}

La larga crisis económica que padece España está teniendo importantes consecuencias sociales. La más comentada por académicos, mass media y parte del arco político es la fractura social que se está abriendo en el país, ante el aumento de las desigualdades económicas que generan el enorme desempleo y las duras políticas de ajuste del gasto público. Sin embargo, más allá de cuestiones económicas la crisis está haciendo mella de forma muy profunda en el imaginario social del país en relación a las razones y consecuencias de la crisis, tanto a corto como a largo plazo. El objetivo de este artículo es el realizar una valoración de esas percepciones sociales de la ciudadanía en relación con la crisis, centrándonos en un aspecto como es el de la relación de la población española con el consumo de bienes y servicios públicos, en un escenario de hegemonía de la austeridad como única receta anti-crisis. Para ello, realizaremos un análisis de los discursos recogidos en una investigación cualitativa realizada en el año 2014 mediante grupos de discusión. Los resultados muestran un pesimismo enorme de la población en relación al futuro del Estado del Bienestar y de la propia clase media española, junto a una frustración que puede anunciar futuros ciclos de movilización social.

${ }^{1}$ Este texto resume una intervención de los autores en el Encuentro Intercongresual sobre Sociología del Consumo, organizado por el Comité de Investigación de la Federación Española de Sociología en enero de 2015; y es producto de los trabajos y publicaciones realizados por los autores en el marco de proyecto de investigación del Ministerio de Economía y Competitividad CSO 2011-29941. Agradecemos a los revisores sus comentarios sobre las versiones anteriores del manuscrito. 
Palabras clave: imaginario social; crisis; clase media; austeridad; análisis del discurso.

\title{
From the Morals of Sacrifice to the Consciousness of Precariousness A Qualitative Analysis of Discourses regarding the Evolution of the Crisis in Spain
}

\begin{abstract}
The long economic crisis affecting Spain has brought major social consequences. The increasing social divide inside the country is the most discussed topic among academics, mass media and members of the political spectrum, being the result of growing economic inequalities due to high unemployment and harsh adjustment policies of public spending. However, and beyond economic issues the crisis is taking its toll very deeply in the social imaginary of the country, bringing further reflections about the reasons and consequences of the crisis, both in short and long term. The aim of this paper is to explore the social perceptions of the Spanish citizens about the crisis, focusing on aspects such as how Spaniards perceive the consumption of public goods and services, in a scenario of a clear hegemony of austerity as the only anti-recession remedy. To do so, a discourse analysis on focus groups transcriptions (collected during a qualitative research conducted in 2014) will be carried out. The results show a huge pessimism about the future of the welfare state and the Spanish middle class itself, whose frustration may lead to future waves of social unrest.
\end{abstract}

Key words:social imaginary; crisis; middle class; austerity; discourse analysis.

\section{Referencia normalizada}

Alonso L. E., C. J. Fernández Rodríguez y R. Ibáñez Rojo (2016): "De la moral del sacrificio a la conciencia de la precariedad. Un análisis cualitativo de los discursos sobre la evolución de la crisis en España", Política y Sociedad, 53 (2), pp. 353-379.

Sumario: Introducción. 1. La nueva conciencia de la precariedad. 2. El temor al desclasamiento. 3. Los ajustes sociales y los límites del desgaste de «lo público»: entre la racionalización y el soporte ideológico de las movilizaciones. 4. Conclusión. 5. Bibliografía.

"La incertidumbre y la vulnerabilidad humana son los cimientos de todo poder político"

Zygmunt Bauman (2011:75)

"En nuestra economía global enfrentamos un problema formidable: el surgimiento de nuevas lógicas de expulsión"

Saskia Sassen (2015:11)

"El miedo es, históricamente, la emoción más importante en economía"

John Lanchester (2014: 13) 


\section{Introducción}

El objetivo de este artículo es realizar una valoración de las representaciones sociales de la ciudadanía en torno a la crisis, tal y como hemos realizado en varios trabajos anteriores (Alonso, Fernández Rodríguez e Ibáñez Rojo, 2011, 2012 y 2015) centrándonos, en este caso, en la relación de la población española con el consumo de bienes y servicios públicos, en un escenario de crisis profunda del Estado del Bienestar (y con el paralelo fortalecimiento de un Estado Workfare que, en el caso español, se ha consolidado de forma manifiesta en el último lustro) y una hegemonía absoluta de la austeridad y los recortes de gasto público como única receta anti-crisis. Para ello, realizaremos en este trabajo un análisis de los discursos recogidos en una investigación cualitativa llevada a cabo en 2014 mediante grupos de discusión, y que, de hecho, duplica otro trabajo de campo realizado a principios de 2010 con el mismo número de grupos, así como con la misma composición y asignación geográfica y sociodemográfica² .

${ }^{2}$ Las Reuniones de Grupo (RG) que se realizaron en esta segunda oleada de principiosmediados de 2014, fueron las siguientes: 1) R.G.1. EMPRESARIOS SECTOR DE LA CONSTRUCCIÓN Y HOSTELERIA (en adelante: RG1-EmpConstrucción). Hombres 55-65 años, todos con varias propiedades inmobiliarias. Algunos participantes vinculados a empresas afectadas por la crisis. Dueños o directivos de medianas empresas del sector. Sin formación universitaria. Lugar de celebración: Málaga. 2) RG. 2. AMAS DE CASA (en adelante RG2AmasdeCasaAlta). Mujeres 45-55 años. Esposas de ejecutivos de nivel alto en el sector servicios. Residentes en urbanizaciones de lujo. Lugar de celebración: Madrid. 3. R.G. 3. PEQUEÑOS PROPIETARIOS RURALES (en adelante RG3-PeqPropRurales). Grupo Mixto 45-60 años. Pequeños agricultores, comerciantes, autónomos y profesionales de un municipio castellano. Lugar de celebración: Arévalo (Valladolid). 4) R.G. 4. EMPLEADOS DE RANGO MEDIO EN EL SECTOR SERVICIOS (en adelante RG4-EmpleadosMedios). Grupo mixto 25-35 años. Empleados de oficina en sector servicios (seguros, banca, energía, telecomunicaciones, etc.). Diplomados o licenciados en titulaciones no técnicas. Algunos participantes en situación de desempleo. Lugar de celebración: Zaragoza. 5) R.G. 5. FUNCIONARIOS DE RANGO MEDIO (en adelante RG5-Funcionarios). Grupo mixto 35-45 años. Funcionarios de rango medio en cualquier ámbito de las Administraciones Públicas (estatal, regional, municipal) (Inspectores de Hacienda o de Trabajo, secretarios judiciales, etc.). Lugar de celebración: Pamplona. 6.) R.G. 6. AMAS DE CASA DE CLASE BAJA (en adelante RG6-AmasdeCasaBaja). Mujeres 35-45 años Con al menos dos hijos menores de edad Nivel educativo máximo: educación obligatoria Con maridos asalariados de pequeñas o medianas empresas Lugar de celebración: Sevilla. 7) R.G. 7. TRABAJADORES ESPECIALISTAS EN GRANDES EMPRESAS INDUSTRIALES Y DE SERVICIOS (en adelante RG7-TrabGrandesEmpresas). Hombres 50-60 años. Sin hijos a su cargo. Trabajadores especialistas fijos, en plantilla de grandes empresas. Nivel educativo requerido: educación obligatoria /equivalente a formación profesional. Lugar de celebración: Área metropolitana de Madrid. 8). R.G. 8. TRABAJADORES JÓVENES HOSTELERÍA (en adelante RG8-JóvenesHostelería). Grupo mixto 20-30 años. Nivel de estudios máximo: Educación obligatoria. Algunos participantes en paro, todos con trayectorias de contratación temporal. Lugar de celebración: Palma de Mallorca. 9) R.G. 9. BECARIOS Y TRABAJADORES EN FORMACIÓN (en adelante RG9-Becarios). Grupo mixto 25-35 años. Nivel de estudios mínimo: Licenciatura / Ingeniería Universitarios en prácticas o becarios con niveles de ingresos bajos pero alta cualificación. Integrados en grandes empresas o instituciones de investigación. 
Estos nueve grupos de discusión han sido organizados e interpretados siguiendo la línea teórico-práctica marcada por la denominada Escuela Cualitativa Madrileña y otros autores cercanos a la misma (Ortí, 1986; Martín Criado, 1997; Alonso, 1998, Callejo 2001; Conde del Álamo, 2009). El enfoque cualitativo que hemos seguido aquí, por tanto, tiene su base en una interpretación sociológica de los discursos, lo que supone un análisis contextual donde los argumentos toman sentido en relación con los actores que los enuncian, enmarcados en el conjunto de fuerzas sociales en conflicto que los originan. El hacer interpretativo de la investigación social es un querer saber sobre el hacer de los discursos, esto es, una práctica de atribución de sentido de los discursos centrada sobre lo que los discursos hacen en la sociedad. Esto representa, justamente, lo contrario de una lectura analítica de los textos -que trata de encontrar un perfil estructural dividiendo su texto en partes y subpartes-; es una lectura activa en la que las preguntas que se le hacen al texto se realizan desde una polifonía de las diferentes posiciones sociales que entran en el campo social de referencia (Bajtin, 1978). Toda interpretación se efectúa dentro del marco de un conflicto de interpretaciones -utilizando la terminología de Paul Ricoeur (2003)- porque toda interpretación se hace en la encrucijada de la pluralidad de sentidos de lo social. Nuestro enfoque de la sociología cualitativa se mueve en este plano conflictivo, por cuanto la labor del lenguaje no se estudia como producto final, sino en tanto que vehículo de captación y comunicación de los sentidos referidos al marco social de los mensajes. La interpretación, por tanto, es el descubrimiento del sentido en el encuentro intersubjetivo entre el sujeto como generador de sentido y el marco social que se encuentra como límite de los significados. La interpretación adquiere sentido cuando reconstruye, con relevancia, el campo de fuerzas sociales que ha dado lugar a la investigación, y cuando su clave interpretativa es coherente con los propios objetivos concretos de la investigación; un doble enfoque pragmático -pragmática de los discursos sociales, pragmática de la estrategia de la investigación- que se diferencia del formalismo lingüístico o matemático, aunque puede encontrar ahí herramientas fundamentales, como de cualquier anhelo de sobreinterpretación basado en un a priori teórico. El análisis sociológico de los discursos tal como aquí lo realizamos es un trabajo sociohermenéutico (Alonso, 2013), no busca códigos universales o estructuras subyacentes por debajo de los enunciados, sino el significado de las acciones de los sujetos sociales situados, yendo del texto a la acción, del enunciado al sentido de las prácticas de los actores.

En este sentido, la estructura narrativa que hemos construido para nuestro análisis requiere algunas aclaraciones previas. La necesidad de síntesis no permite realizar un despliegue analítico que respete las diferentes posiciones discursivas que han surgido en el interior de cada grupo ni una identificación precisa de cuál ha sido la relación de fuerzas concreta dentro de cada perfil social de nuestra muestra. Frente a ello, hemos optado por intentar presentar los tres ejes discursivos más significativos según nuestra interpretación (considerando además los cambios que han tenido lugar respecto al análisis de investigaciones anteriores), ejes que no respetan necesariamente una distinción por

Lugar de celebración: Barcelona. Las transcripciones de todos estos grupos están disponibles para que cualquier investigador o investigadora interesada pueda consultarlas y utilizarlas en sus trabajos si le son de utilidad. 
clases sociales aunque intentan recogerla en cierta medida. En primer lugar, en el epígrafe segundo tratamos de presentar el trasfondo sobre el que giran los cambios en los discursos de los grupos de perfil medio y bajo. Bajo la idea de una nueva conciencia de la precariedad tiene lugar por una parte una pérdida de eficacia de los discursos de autoculpabilización y, por otra parte, una crítica creciente a la evolución de las condiciones laborales. En segundo lugar, en el epígrafe tercero se recoge la nueva centralidad que el temor específico al desclasamiento está ocupando en los discursos de los perfiles medios y altos. ${ }^{3}$ El cuarto epígrafe trata de mostrar la polarización y diversidad de posiciones enfrentadas (entre los grupos y en el interior de algunos de ellos) respecto a las movilizaciones en defensa de los servicios públicos. Tal y como explicamos más adelante, este eje fue precisamente introducido en las dinámicas de los grupos como un analizador de la fuerza o la debilidad de la posiciones discursivas más mediadoras de las "clases medias". Si bien de una forma muy tentativa, se trataba de analizar aquí hasta qué punto los discursos recogían la aparente deslegitimación del modelo económico y político del que se habían intentado hacer portavoces las movilizaciones en favor de los servicios públicos. Y, finalmente, el apartado de conclusiones trata de reconstruir esos ejes analíticos que hemos presentado en tanto que un cambio en torno a los discursos más generales sobre la crisis.

\section{Una nueva conciencia de la precariedad}

En los análisis que hemos realizado en otros trabajos (especialmente en Alonso, Fernández Rodríguez e Ibáñez Rojo, 2011), habíamos podido rastrear en los discursos de los grupos de diferentes perfiles sociales el efecto ideológico de disciplinamiento que las críticas moralistas sobre los excesos del consumo habían orientado hacia los sectores populares. El sedimento de estas críticas puede verse circulando abiertamente una vez se ha tomado plena conciencia en todos los perfiles sociales de la profundidad de la actual crisis económica. De hecho, los ideologemas ${ }^{4}$ en torno al endeudamiento y el consumismo de los sectores populares siguen funcionando en la actualidad y

${ }^{3}$ La composición de los grupos intermedios en el contexto actual ha generado una polarización de posiciones discursivas que resulta de por sí significativa, pero que implica que circulen en su interior argumentos afines tanto a lo defendido en los perfiles de clase alta como en los de clase baja. Por ello, los perfiles medios ocupan un lugar central del análisis en ambos epígrafes pues no es posible, dentro de la necesaria brevedad del texto, entrar en las singularidades que diferencian a cada uno de ellos y a su vez respecto a los perfiles altos y bajos.

${ }^{4}$ Siguiendo a Voloshinov (1976), entendemos por ideologemas aquellos puntos de condensación que expresan simultáneamente un punto de conflicto y un «retazo» de la subjetividad de los hablantes y son, en ese sentido, un elemento que puede funcionar como decodificador de un universo ideológico. A través de ellos intentamos reconstruir las marcas que el conflicto social deja en los discursos, es decir, lo que Göran Therborn denomina el «proceso de la ideología», asumiendo siempre que "las ideologías, contrariamente a la concepción tradicional en la historia de las ideas, funcionan realmente con un cierto desorden" (Therborn, 1987: 67). 
han cristalizado en una lección bien aprendida por algunas fracciones de los sectores populares entrevistados:

“-A mí, desde luego me ha enseñado, esto. Porque... yo era bastante de comprar tonterías. Tonterías en el sentido de que no me hacían falta. No me hacía falta. Y ahora, aunque la cosa cambie, que Dios lo quiera, y en mi casa vuelva a entrar un buen sueldo, yo voy a intentar seguir como estoy hasta ahora, y no gastar en esas tonterías $[\ldots]$

-Sí. Sí, porque esto nos ha enseñado. Esto es un palo que nos ha enseñado. Por lo menos a mí la primera. A mí me ha enseñado. Porque yo pensaba, cuando ya vino todo esto, Dios mío de mi alma, si no hubiera gastado esto en esto, si no hubiera gastado lo otro, yo ahora tendría, a lo mejor, equis dinero más en el banco, que ahora no tengo. Que ahora me hace falta. Te enseña. Esto te enseña." (RG6-AmasdeCasaBaja)

Sin embargo, este conjunto de grupos de discusión, realizado ya tras seis años de crisis económica, permite reconstruir algunos cambios significativos en las posiciones discursivas y su eficacia simbólica respecto a nuestras principales conclusiones en trabajos anteriores. El breve recorrido del análisis que aquí nos proponemos recoge algunas de las cuestiones que los cambios habidos en nuestro país durante los últimos meses han convertido en gran medida en evidentes, pero que nuestros grupos anticipaban y anunciaban. Sin duda alguna la extensión de la crisis económica está modificando de manera significativa los discursos (o al menos su fuerza relativa) en torno a la estructura y el cambio social. A pesar de ello, el discurso culpabilizador hacia las clases bajas sigue absolutamente presente en todos los perfiles medios y altos, pues en todas las dinámicas sigue apareciendo la posición que defiende que "es obvio que hay gente que realmente ha vivido por encima de sus posibilidades" (RG9-Becarios). Las posiciones moralistas que critican la falta de educación y de cultura entre quienes se endeudaron en exceso sigue muy activa, pero han tenido lugar dos movimientos que han debilitado su eficacia (para el disciplinamiento). Por una parte, la responsabilidad y el interés de la banca en el endeudamiento de las familias se ha hecho ya evidente para todos los grupos y su deslegitimación (tras los últimos casos de corrupción y mala gestión) facilita desplazar hacia ella la responsabilidad de los excesos. Pero, por otra parte, se ha fortalecido (entre los grupos medios y bajos) el argumento de que el problema no ha sido un afán descontrolado por acceder a los privilegios de las posiciones más acomodadas, sino una falta de conciencia sobre la posición de subordinación y dependencia que ocupa el trabajador asalariado.

En este sentido, aunque sigue siendo mayoritaria una posición pesimista respecto a un cambio en las pautas de consumo («cuando la economía vuelva a crecer volveremos a consumir igual»), es como si lo aprendido con la crisis fuera que los sueldos pueden bajar o desaparecer en cualquier momento. Hay una cierta conciencia de que el ajuste ha supuesto un cambio en la posición de fuerza de los trabajadores, que les ha recordado el hecho de que su posición se sustenta en la incertidumbre, por lo que los grandes gastos deben ser pensados con frialdad. En los términos de los empleados medios de Zaragoza "ha cambiado los modelos de derechos de los trabajadores... [y] yo creo que la gente se lo pensará un poco más a la hora de firmar un préstamo" (RG4-EmpleadosMedios). 
Desde perspectivas paralelas, varias posiciones discursivas en los grupos de perfil medio y bajo reflejan una toma de conciencia de la fragilidad de su posición social, facilitando una mayor eficacia a los discursos de defensa y de resistencia frente a la estrategia de los ajustes y la culpabilización.

Es por ello que podemos considerar un primer cambio muy significativo con respecto al comienzo de la crisis, puesto que lo que ya no asumen los grupos de perfil más popular es la culpabilidad sobre la situación de crisis económica ni sobre la mayor o menor degradación de sus condiciones de vida. En todos los grupos de perfil bajo o medio, siguen apareciendo en un primer momento de las dinámicas posiciones discursivas acordes con el mensaje de castigo hacia quienes «vivieron por encima de sus posibilidades». Los restos culturales de la austeridad obrera siguen imponiendo la autocrítica y exigiendo asumir una cierta responsabilidad en lo ocurrido. Pero, en gran medida, esta posición pretende señalar cómo muchos (dentro de su misma clase social) habían olvidado la precariedad que define a la condición obrera. La disciplina en el gasto, la represión de los impulsos consumistas forman parte de las estrategias de autodefensa de su posición de clase.

“... en mi vida he comprado a crédito. Hasta que estoy en crisis. Ahora sí he usado el crédito alguna vez. Pero yo en mi vida he comprado a crédito, porque siempre he sido una persona que lo que no tengo, no lo compro. Y si no tengo, no pago. Y, es verdad, que aunque sea culpa de los bancos, que yo no le estoy quitando culpa a los bancos, pero es que también algo de culpa nos tenemos que echar a nosotros mismos. No tú como persona, pero..." (RG6-AmasdeCasaBaja)

Y en cualquier caso, sí ha tenido lugar un desplazamiento en los discursos centrales de los grupos hacia una mayor culpabilización de los bancos, que habrían sido los realmente interesados en el préstamo fácil. Desde el punto de vista de las familias el problema no era un excesivo endeudamiento sino esa escasa conciencia de la precariedad de la relación salarial, pues "si mantuviera ese ingreso de ese momento, podría haber pagado el préstamo seguramente y sin ningún tipo de problema. El problema es que se ha reducido los ingresos a todos los niveles, donde se hacían horas extras, ya no se hace ni una hora extra, encima se reduce un veinte o treinta por ciento el salario, con lo cual..." (RG4-EmpleadosMedios).

Pero frente a lo que ocurría unos años atrás, la crudeza de la situación actual de crisis, las experiencias directas o indirectas sobre quienes lo están pasando muy mal con la crisis, sobre la degradación de las condiciones de trabajo, los pagos a destajo a precios cada vez más bajos, el auge de la informalidad y la ausencia de protección, etc. En definitiva, la conciencia sobre el volumen de familias con ingresos mínimos que apenas pueden luchar por sobrevivir margina cualquier posición discursiva que pretenda generalizar la degradación moral de la condición obrera (el hedonismo sin control) como causante de la crisis. Esta manera de intentar imponer una asunción de responsabilidades personales, es más bien una llamada al cambio y a la intervención concreta para mejorar la situación, es decir, una crítica al pasotismo que implica señalar a los bancos y los políticos como únicos responsables: 
"Bueno, ha habido engaños, que yo no te digo que no haya engaños, pero que todo es culpa de los bancos y que todo es culpa del gobierno... Si sólo es la culpa de los demás, nunca solucionaremos los problemas. Si la culpa de que a mí me vaya mal es de los bancos y del gobierno siempre va a ir mal. Porque el banco y el gobierno no se va a preocupar de que a mí me vaya bien.” (RG6-AmasdeCasaBaja)

En este sentido, si bien tiende a asumirse la crítica lanzada por las posiciones supraordinadas desde el comienzo de la crisis, la posición hegemónica entre los sectores medios y bajos es considerar que se trata de casos minoritarios y muy poco relevantes a la hora de explicar la crisis y encontrar sus causas. Pero más allá de esta lección moral, los dos grupos de jóvenes parecen sintetizar adecuadamente la otra lección que se desprende de los discursos: el error de algunos no fue tanto el de caer en las garras del consumismo sino el de olvidar que un contrato indefinido no es un contrato fijo, que la condición actual del trabajador asalariado es la máxima eventualidad. El problema es entonces que "nadie se planteaba que el trabajo no durara toda la vida", lo que desde la trayectoria habitual del joven trabajador español ha pasado a ser "información de Perogrullo" (RG9-Becarios).

De hecho una fracción de los jóvenes enuncia una cierta defensa de vivir al día (frente a las posiciones más austeras de un discurso obrero más adulto y más pensado desde la lógica del sustento familiar). Es la posición extrema del discurso de los jóvenes precarios, aunque planteado desde un perfil relativamente acomodado (si bien con escasas o nulas posibilidades de promoción), que convierte la temporalidad y la concatenación de contratos en una condición de vida. Obviamente esta posición se asienta en el relativo privilegio de una región con empleo precario pero abundante, al menos durante ciertos meses del año. Pese a ello, sí representa un eje discursivo común para racionalizar determinadas resistencias de algunos grupos de jóvenes hacia la extensión de condiciones de trabajo cada vez más precarias ${ }^{5}$. Desde esta posición carece de sentido la lógica de la disciplina obrera, del ahorro, etc. para conseguir una cierta estabilidad; pues en las condiciones actuales el sacrificio no merece la pena.

"Bueno, es que yo pienso, a ver, es que parece que ahora todo el mundo dice: "no, es que tienes que ahorrar, es que tienes...". Vamos a ver, si yo gano 1.000 euros y me puedo permitir comprarme 500 en ropa: “ah!, ¿cómo vas a gastar esa barbaridad?”. Es que ¿para qué trabajo, para guardar?” (RG8-JóvenesHostelería)

De hecho, desde las fracciones más críticas de estos grupos la eventualidad debe convertirse en una herramienta de libertad para el trabajador, que debe aprender a contar con ella y a saber manejarse en ella:

“-Sí, a la gente también le vendieron que ser fijo era tener una garantía y... (se ríe) -Claro.

${ }^{5}$ Un breve análisis de los discursos juveniles ante la crisis lo realizamos en Alonso, Fernández Rodríguez e Ibáñez Rojo (2012). 
$-\mathrm{Y}$ ahora pues...

-En su momento tal vez lo era; en su momento tal vez sí.

-Yo cuando me vayan a hacer fija me voy de la empresa, no quiero ser fija; ni he sido ni lo seré en la vida fija. ¿Para qué?, ¿para que luego me puteen y yo me vaya y pierda toda mi...? Me voy a otro trabajo, siete meses y cambio.

- Tal vez en tu caso ocurrió así.

-Pero es que ser fijo no te garantiza nada, al revés: ahora te pueden putear y si tú te vas pierdes todo.

-Exacto, yo estoy en esta situación ahora mismo, por ejemplo; soy fijo en un sitio hace tres años y medio y, lo que tú dices, estar fijo a veces te... te quieres pegar un tiro porque te hacen las mil y una, tienes que aguantar. ¿Todo por qué?, porque sabes que si sales dejas un trabajo fijo..." (RG8-JóvenesHostelería)

La condición precaria implica un modelo de consumo completamente desligado del acceso a la propiedad, y en ese sentido una ruptura con la lógica del sacrificio y el ahorro orientado a consolidar un patrimonio. Desde la posición más activista se trata de adaptar el modo de vida a un consumo muy modesto para no entrar en los altos niveles de explotación laboral a los que habría que someterse para reproducir los viejos modos de consumo y de acceso a la propiedad. Sin embargo, los jóvenes de nuestra RG8 (trabajadores jóvenes de la hostelería) son conscientes de que sólo pueden jugar con buenas herramientas en el marco de la eventualidad quienes cuentan con un buen respaldo familiar para salir adelante en los peores momentos y convertir en resistencia cotidiana sus relaciones personales en el trabajo: "Claro, pero... yo igual que tú, soy una persona que estoy superrespaldada, no tengo por qué tragar mierda con nadie, entonces a la mínima de cambio yo a mis jefes les digo: "oye, ¿qué no te gusta?, pues adiós, tengo otro curro" (RG8-JóvenesHostelería). Frente a esta exigencia lo habitual, cuando el apoyo y la cobertura familiar no es tan fuerte, es que la situación de paro reprima cualquier crítica o cualquier intento de resistencia.

"Yo conozco mucha gente que a lo mejor cobra mucho pero que está muy puteado y trabaja 70 horas a la semana, pues tampoco es una forma, ¿no? o que echan a gente de su equipo y dicen no le vamos a sustituir, vas a coger tú su trabajo, que también es eso al final mirando desde abajo, los que miramos desde abajo también es como tú no tienes derecho a quejarte, parece que ya nadie se puede quejar, si cobras un sueldo a final de mes no te puedes quejar de nada" (RG9-Becarios)

Estas posiciones simplemente recogen el hecho de que la situación laboral se mueve ya en el límite de lo "tolerable", al menos entre los jóvenes con un cierto grado de cualificación, que son los mejor representados en nuestra muestra cualitativa. Ellos dan cuenta desde sus experiencias de lo que las estadísticas y los medios de comunicación están reflejando sobre la creación de empleo en nuestro país. Esta posición relativamente crítica hacia la evolución de las condiciones de trabajo y hacia la conciencia de la precariedad como posición compartida, no ha cambiado el hecho de que el nivel educativo funcione como clave para la distinción y para impedir la construcción de 
una identidad colectiva en torno a dicha condición precaria ${ }^{6}$. En la lucha dentro de la escasez de trabajo, aquellos que han tenido acceso a los estudios exigen un reajuste, e incluso elaboran un discurso coherente con la re-elitización de la enseñanza superior: "Yo creo que es un poco el reajustarlo porque antes de la crisis era mogollón de facilidades: becas, todo para poder estudiar y se ha formado a demasiada gente y no podemos asumir todos esos puestos de trabajo. Entonces yo creo que la idea ahora es que haya menos gente que estudie, ya que tenemos un montón de gente formada que no va a trabajar nunca de lo suyo, entonces es un..., yo creo que es un pequeño reajuste" (RG8-JóvenesHostelería). Aun así, dentro del propio grupo tiene lugar un conflicto con las posiciones más subordinadas que se niegan a considerar que el nivel educativo en sí mismo se convierta en un privilegio a la hora de encontrar trabajo:

"Claro, pero ¿ves?, dices: es normal. No es normal, o sea, o es que yo..., o por lo menos yo tengo muchos menos estudios que vosotros o soy más inculta pero a mí no me parece normal que para hornear tres barras de pan... «No, es que es normal, porque como hay tanta gente preparada», no, lo normal sería que hubiese trabajo para todos. Es que si nos ponemos así yo nunca tendría un trabajo." (RG8-JóvenesHostelería)

Esta tensión, que fragmenta las posiciones discursivas elaboradas desde la trayectoria de precariedad juvenil, no está muy presente en nuestras dinámicas (debido a los perfiles finalmente seleccionados), pero indica esa dificultad para traducir la conciencia de la precariedad en algo más que un diagnóstico. A pesar de ello, las posiciones mayoritarias en los grupos sí hacen patente esta relativa toma de conciencia sobre la debilidad del trabajador asalariado, y hacen patente su papel ideológico como elemento de resistencia frente a los discursos más disciplinarios elaborados en los primeros años de la crisis.

\section{El temor al desclasamiento}

La profundidad y la duración de la actual crisis económica en España también ha modificado significativamente los discursos de los perfiles de estatus medio y medio alto. Si una mayor conciencia de la precariedad ha articulado algunos cambios sustantivos en las posiciones discursivas de los grupos de perfil medio y bajo, es la potencia de un discurso - construido específicamente en torno a los hijos- sobre las dificultades para reproducir la condición de clase lo que da sentido a los cambios que reflejan las dinámicas de nuestros grupos de perfil medio y alto. Si la precarización impide —al margen de una identificación superficial - elaborar discursos desde una posición de clase media entre los grupos de origen más modesto, la perspectiva de una degradación

${ }^{6}$ Sobre el tema de la precarización y el precariado como nueva condición social y, la más problemática identidad política del precariado pueden verse los trabajos de Alonso (2007) y Alonso y Fernández Rodríguez (2013a) en nuestro entorno, Standing (2013 y 2014) en el ámbito anglosajón, y Paugam (2007) o Cingolani (2015) en la tradición francófona. 
estructural de las condiciones de vida y un endurecimiento de la competencia en el mercado de trabajo, debilita igualmente esa posibilidad entre los grupos de perfil medio. De la misma forma que tiende a radicalizar hacia posiciones defensivas a los grupos y posiciones de perfil más alto.

Por una parte, es como si se hubiera hecho evidente que "hay otra España", la visibilización de la desigualdad social (especialmente a través del drama siempre mencionado de los desahucios) ha abierto inevitablemente los ojos a la magnitud del empobrecimiento de una parte de la población española:

"Claro. Hombre, tienes uno... Vamos a ver, claro, no son situaciones críticas como las que estamos viviendo y viendo de gente pues que, que, que van a los comedores sociales. Realmente hay otra España. Yo esa no la estoy viviendo. Entonces pues la verdad dices, pues si no me compro tres faldas, me compro una. Y si no puedo viajar a tal, pues viajo a Toledo, que está más cerca y es muy bonito. Y yo pues me siento también una privilegiada." (RG2-AmasdeCasaAlta)

Las posiciones que consideran moderados los efectos de la crisis, que en años anteriores podían circular con mayor libertad, son ahora inmediatamente contestadas en el interior de las dinámicas. Aunque se trate de perfiles que sólo han tenido que renunciar a gastos considerados por ellos mismos como secundarios, lo cierto es que hay otra realidad innegable: "Hombre, mucha gente hablamos de perder pisos y todo eso quiero decir que no hablamos solo de tomar un café fuera" (RG9-Becarios). Pero a pesar de esa visibilidad de la España de los desahucios y de los bancos de alimentos, en el grupo de funcionarios se plantea incluso la sospecha de que el empobrecimiento latente de las clases medias sea incluso mayor.

"Yo lo que sí he percibido con esta crisis es la dificultad de la gente para reconocer una mala situación o para pedir ayuda en un momento determinau o... tenemos como un no sé, como una dignidad mal entendida y me da la sensación de que las cosas, muchas veces son más graves de lo que vemos o de lo que nos dejan ver. Precisamente por eso, a mí me han tocau casos cercanos en los que yo sé más allá de lo que veo, pero, pues la persona no pide ayuda. Pues porque le parece, no sé, algo de... no sé. Es difícil." (RG5-Funcionarios)

También se ha tomado conciencia de la descomposición del modelo político y del modelo de crecimiento económico sobre el que se había sostenido la reciente etapa de prosperidad. No hay ya una distinción evidente entre la crisis económica y la crisis política e institucional, lo que también ha ido desplazando las responsabilidades sobre la situación de crisis. En varios de los grupos se plantea que no eran conscientes de la magnitud de la corrupción, tanto en el ámbito financiero como en el político. Las mujeres de clase alta de Madrid lo plantean con la inocencia de quien no podía ni imaginarlo:

"-Bueno yo de lo que me he dado cuenta es de lo ignorante que he vivido toda la vida. O bueno toda la vida, o esta vida que teníamos antes. Porque de repente dices, 
uy pues que es que resulta que los bancos están robando, porque roban, o sea a ver... Porque si ahora encima esos bancos no favo... [...]

-Yo para nada. ¿Yo pensar que todo el mundo estaba en esa corrupción?" (RG2-AmasdeCasaAlta)

Pero como señalábamos, lo más significativo es que la situación de crisis se vive ahora fundamentalmente a través de la percepción del riesgo de desclasamiento 7 que experimentan los hijos. Dado que sus ingresos están por lo general protegidos, sus prácticas cotidianas y su percepción de la crisis sería muy moderada: "a mí personalmente me ha influido más por el hecho de pensar en mi hijo, en mis hijos" (RG2-AmasdeCasaAlta). Pero la preocupación por la gente joven aparece ya en las primeras intervenciones y lo hace de forma sistemática en varios grupos. Quienes hablan desde la posición de padres (especialmente RG1-EmpConstrucción y RG2AmasdeCasaAlta), señalan que pueden adaptarse sin problema a la austeridad, pues ya la han conocido anteriormente, pero el problema son sus hijos:

“Evidentemente, en el cambio de hábitos se está notando. Yo lo estoy notando, lo estoy inculcando a mis hijas porque ciertamente, como bien han dicho los compañeros, creo que ninguno, no solamente los que estamos en esta mesa, sino en general, muy poca gente miraba los precios. Muy poca gente. Empresarios o no empresarios. Ni miraban los precios ni para comprar tanto en consumo, como en vivienda, como en coche, como en cualquier cosa. [...] Luego nosotros, que hemos vivido en la austeridad, y algunos con necesidades. Con necesidades. Y hemos estado después en la abundancia, nos cuesta, nos cuesta volver. Pero podremos adaptarnos. Yo lo hablo personalmente por mí. Lo difícil, como decía 2, son nuestros hijos. Es muy difícil decirle tú a un hijo que por qué el año pasado le comprabas una tablet, la equis-equis, y este año no le puedes comprar un móvil.” (RG1-EmpConstrucción)

Es esta angustia por el futuro lo más determinante en la construcción del discurso hegemónico. No se percibe la salida de la crisis y los discursos denotan la creación de estrategias defensivas dentro de un modelo social y económico cada vez más fracturado y más desigual. Ese futuro de progreso estable, condición necesaria para la eficacia simbólica de los discursos sobre las clases medias ${ }^{8}$, parece imposible de dibujar, y los grupos difícilmente encuentran anclajes para un discurso optimista. El milagro

${ }^{7}$ El debate sobre el desclasamiento, la quiebra de la promoción social de las clases medias y el descenso generacional de las oportunidades vitales de las clases medias y populares ha sido uno de los más ricos en la sociología francesa actual, véanse por ejemplo el muy difundido trabajo de Chavel (2006) complementado -polémicamente- por el no menos interesante libro de Maurin (2009). Muchas de sus conclusiones han servido de marco de referencia para nuestro análisis de los discursos sobre el tema.

${ }^{8}$ El tema teórico de la quiebra -simbólica y material- de las clases medias herederas de la edad de oro del Estado del bienestar es uno de los temas más recurrentes en la literatura sociológica actual, para seguir el tema véanse Gaggi y Narduzzi (2006), Cowen (2014) y Hernández (2014). 
del crecimiento económico español se define como ficción y cuando se piensa en las bases materiales para un futuro estable es imposible encontrarlas. "¿Qué argumentos hay?" para salir de la crisis económica, se preguntan las amas de casa madrileñas: “¿Tenemos empresas? ¿Tenemos industria? ¿Tenemos? ¿En qué? Es que eso no lo estamos fomentando. ¿Cómo vamos a salir de aquí?" (RG2-AmasdeCasaAlta). Incluso quienes representarían a los hijos de estas posiciones sociales han podido captar cómo sus padres, de clases medias o relativamente acomodadas, han tenido que renunciar a algunos elementos de distinción para mantener un cierto nivel de vida, han tenido que recortar en las señales más secundarias de jerarquización de los mercados para maximizar los ahorros orientados a la reproducción de la condición de clase de sus hijos.

"Igual sí que, no sé, para ser un poco optimista, y lo que comentabas tú también, yo recuerdo hace años comprar en el DIA o marcas blancas había como la coña de esto es basura, cierta gente decía hombre es que te comes eso y es cancerígeno, o en el Lidl argg... sabes, pues alguna de esta gente que solo compraba Pascual, tal o muchas madres también como muy de marcas no sé, yo conozco mucho a amigas de mi madre que es todo El Corte Inglés, Leche Pascual, como estas grandes empresas de España de tal, pues que están comprando marcas blancas." (RG9-Becarios)

Resulta también muy significativo que quienes con más crudeza han experimentado el auge y caída de la economía española, dibujen a Sudamérica y su estructura social oligárquica como el modelo más probable para el futuro de España. Un futuro marcado por una creciente polarización, con "una gran clase asalariada y una clase dirigente, propietaria de las grandes empresas. Yo, que vengo ahora, analizo mucho Sudamérica, Sudamérica es así. [...] Y quizás sea España, España pueda verse, espero que no, en ese escenario, que es que se adelgace esa clase media, el camino hacia la igualdad de oportunidades se reduce y al final son cuatro o cinco multinacionales, la banca, cuatro o cinco familias, propietarios de las multinacionales, y luego un montón de asalariados que, prácticamente no tienen otra opción que..." (RG1-EmpConstrucción). De forma muy similar se expresan los trabajadores especialistas al señalar cómo el abaratamiento de los costes de la mano de obra es la condición de posibilidad del nuevo modelo de negocio que estaría sustituyendo a la burbuja inmobiliaria. La extensión de los trabajadores pobres y de una promesa permanentemente incumplida de redistribución definiría el nuevo "negocio":

"Yo es que pienso que la crisis es un negocio que funciona muy bien. Y como todo, lo van a mantener. $\mathrm{O}$ sea, ha habido un cambio de modelo, de un tiempo donde pues eso vivir por encima de las posibilidades consistía en que tú generabas demanda, te inyectaban un capital, ellos inyectaban dinero, y tú generabas demanda y se producía todo un círculo. [...] Aquello era un negocio y ahora éste es otro. Y éste es el negocio donde hay un sector muy, muy, muy depauperao, muy, muy deprimido... Y sobre ese caldo de cultivo pues les está yendo cojonudamente: bajan costes, reducen costes permanentemente y pueden reportar mejor, no sé qué, no sé cuántos... Que yo creo que para mí es un negocio, porque están diciendo "tenemos intenciones 
de salir de la crisis" y lo que están diciendo es que como "seguid trabajando que en un futuro, algún día a lo mejor, unas migajas os van a tocar..." (RG7-TrabGrandesEmpresas)

En este mismo sentido, en los grupos empieza a instalarse la percepción de que el futuro, aunque cargado de incertidumbre, parece mostrar una tendencia a una desigualdad creciente, en la que derechos que parecían firmemente asentados son susceptibles de desaparecer. La educación universitaria por ejemplo, incluso dentro de un perfil con estabilidad laboral como el de los funcionarios, se ve como algo que en el futuro va a ser difícil de sufragar, así como otras muchas cosas, dentro de una dinámica de desposesión de las clases medias y populares por parte de las élites:

“-Yo soy funcionario, parecía que vivía bien, pero es que no le voy a poder pagar la carrera a estos hijos, por ejemplo, ¿no? Creo que hay unas cosas que antes se daban como por hechas que van a empeorar mucho en el futuro, o vas a tener mucha previsión de ir ahorrando para eso o... [...]

-Yo me da la sensación que la educación universitaria va a ser elitista." (RG5-Funcionarios)

Frente a una posición elaborada desde una identidad de clase media estable que pudiera asumir la privatización —e incluso sentirse beneficiada por ella—, el propio temor de que los hijos e hijas tengan necesidad de la red pública cuando no cuenten con el apoyo familiar, fortalece los argumentos en favor de los servicios públicos fundamentales tal y como trataremos de mostrar más adelante. Ello no es sino el reflejo de que las posiciones intermedias de la estructura social se dibujan a sí mismas sufriendo un evidente deterioro de sus condiciones de vida, hasta el punto de ver en su entorno situaciones de mera subsistencia. En todos los niveles de la estructura social se comparte sin mucho dramatismo - pues la identificación con ellas es siempre superficial-, la idea de unas clases medias en declive, o directamente en proceso de extinción:

"El que tiene dinero tiene cada vez más y el que tiene menos cada vez menos. Es que la clase media está desapareciendo" (RG6-AmasdeCasaBaja)

"La gente que es rica es rica y la gente pobre, cada vez más pobre. Y la clase media que está desapareciendo" (RG2-AmasdeCasaAlta)

"Yo creo que estamos bajando de la media, la clase media yo creo que está desapareciendo." (RG7-TrabGrandesEmpresas)

Pese a ello, la adscripción de la mayoría de los participantes con la clase media sigue siendo casi inmediata, pues otras identidades requerirían de un complejo consenso y una dinámica específica en las reuniones de grupo. Y por ello no es sorprendente que muchos de ellos se presenten como ejemplo vivo de esa tendencia al empobrecimiento. Tras haberse considerado durante una etapa genuinos representantes de las clases medias españolas, hoy certifican desolados su caída, ejemplificada de forma muy significativa a través de su renuncia a los gastos en ocio, pues de lo contrario no se pueden asumir los 
gastos básicos de la vida cotidiana ${ }^{9}$. Obviamente, es entre las posiciones más débiles, que en nuestra muestra representan las amas de casa de clases populares, donde está visión se manifiesta de forma más explícita y más extrema: "Yo antes era una persona, yo que sé, igual que todos los españoles. Pero es que ahora yo soy pobre. Es que yo ahora no me puedo tomar una cerveza, porque si no, mañana no tengo para pagar la luz". La situación se ha ido degradando de tal manera que el grupo llega a dibujar como su condición colectiva una situación en la que uno no llega a fin de mes y debe renunciar a cosas que antes estaban a su alcance, como simplemente tomar una cerveza con los amigos o ir al cine. La cultura se ha convertido para este grupo en algo "de ricos", y aunque no ir al cine no es sinónimo de ser pobre, sí es el síntoma de que "ahora es que vives al día, y cuando llegas." (RG6-AmasdeCasaBaja).

\section{Los ajustes sociales y los límites del desgaste de «lo público»: entre la raciona- lización y el soporte ideológico de las movilizaciones}

Cuando se interpela a los participantes por las políticas de ajuste y la disminución del gasto público, las primeras reacciones tienden a señalar que los recortes en gasto social se han notado poco, que los servicios y prestaciones fundamentales siguen funcionando básicamente igual. Pero inmediatamente van surgiendo diferentes efectos de los recortes, mencionados como experiencias personales, que tienden a ser aceptados por la mayor parte de los participantes. En las diferentes dinámicas surge el tema de los medicamentos, y varios elementos van siendo enumerados no tanto como señal de grandes cambios, sino como desaparición de servicios "adicionales" y de pérdida de calidad: subvenciones que se han quitado a guarderías, médicos que atienden a zonas más amplias que antes, ausencia de conserjes y recortes de material en los colegios, la aparición de las vacunas de pago y de vacunas especiales, etc. Hasta llegar algunos grupos a concluir que se ha recortado "un montón". Los funcionarios, testigos privilegiados en este caso, dibujan un empeoramiento progresivo de la calidad de los servicios como resultado de la reducción de personal, pues coinciden en señalar un enrarecimiento del

\footnotetext{
${ }^{9}$ Camille Peugny (2009:18 y ss.) en uno de los libros más interesantes sobre las consecuencias sociales de la crisis de los modelos de regulación redistributivos, diferencia tres formas básicas de desclasamiento, lógicamente relacionadas entre ellas y que aparecen constantemente como realidad fáctica o como fantasma en todos nuestros grupos de discusión: el intergeneracional, cuando la generación descendiente no logra superar o ni siquiera alcanzar el estatus de la generación anterior, llegando incluso a la pérdida de posiciones sociales; el biográfico, que se evidencia por las pérdidas personales o individuales de estatus, capital social y opciones vitales que se derivan del desempleo, la desafiliación o cualquier contingencia vital; y el educativo o meritocrático, provocado por la devaluación del capital cultural y las credenciales académicas emitidas por las instituciones de enseñanza nacionales. Julien Damon (2013), por su parte pone en relación las pérdidas relativas de capital económico, social, cultural y simbólico de los grupos normalizados por el capitalismo industrial y fordista con el proceso de erosión y penalización de las clases medias francesas, presentando un cuadro muy cercano a la desposesión y distribución antisocial de todo tipo de recursos.
} 
ambiente laboral y a partir de ahí una degradación de la calidad de los servicios: "se ha empeorado todo, ¿no? Todo el ambiente laboral se ha enrarecido, el recorte de plantilla de interinos, de apoyos externos, de presupuesto y todo eso hace la situación un poco dura, ¿no?” (RG5-Funcionarios). En los grupos de jóvenes el principal efecto de los recortes que es mencionado es la reducción en las becas y ayudas para la educación. Pero es significativo que aunque se señale que los servicios públicos en general han empeorado y han sufrido un deterioro más o menos grave, lo cierto es que ningún grupo llega a plantear un derrumbe radical del conjunto de prestaciones y servicios públicos básicos. Obviamente los grupos de perfil más acomodado (RG1-EmpConstrucción y RG2-AmasdeCasaAlta) lo han notado menos, y mantienen de forma mayoritaria una posición según la cual las cosas siguen funcionando razonablemente bien.

Pero más allá de la descripción de la situación, nos interesaba analizar las posiciones ideológicas en torno a los servicios públicos en la medida en que preveíamos debido al crecimiento de las movilizaciones sociales contra los recortes en el gasto público - que podían funcionar como un analizador de la fuerza o debilidad de las posiciones "centristas" (mediadoras, tecnocráticas), representativas de las clases medias. Y ciertamente, estas posiciones ideológicas reflejan una creciente polarización de los discursos ${ }^{10}$, pero que tiene lugar en el interior de los diferentes perfiles, pues casi siempre posturas enfrentadas están presentes en todos los grupos (si bien los argumentos hegemónicos son finalmente diferentes dentro de cada perfil). Es decir, las posiciones son con frecuencia ambiguas e incluso contradictorias en momentos diferentes de la dinámica, lo que simplemente refleja una creciente politización —más o menos contaminada por las cuestiones que más visibilidad adquieren en los medios de comunicación - pero desde posiciones todavía indefinidas, dentro de ese relativo desorden del proceso de la ideología que señala Göran Therborn (1987).

$* * * * *$

Una primera polarización presente en los discursos contrapone los excesos y derroches indiscutibles del gasto público frente a la necesidad de mantener e incluso fortalecer los servicios públicos fundamentales. En torno a estos temas es ya patente la influencia de los medios de comunicación y la creciente politización de sus contenidos según ha ido avanzando la crisis económica. Por ello, en casi todos los grupos están presentes las denuncias sobre los grandes gastos en infraestructuras, desde los aeropuertos vacíos hasta el enterramiento de la M30: "Porque en realidad, yo aluciné, cuando no sé quién

${ }^{10}$ Como dice Terry Eagleton (2001: 186) todo conflicto social abierto implica una polarización de los discursos, lo que implica una concurrencia de poder y significación, las ideologías semantizan los intereses en conflicto y toda significación depende del marco de poderes que las construyen. Para el tema actual de la polarización social sobrevenida en el ciclo histórico de la era neoliberal y la crisis financiera contemporánea -el muy presente tema de la rebelión de las élites y su fuga de cualquier compromiso social frente a la revuelta contra las élites, sus indignaciones, mareas y resistencias-, pueden verse, con carácter introductorio Revelli (2015) y Taibbi (2015). 
lo dijo, que la M30 costó lo mismo que el Canal de Panamá. O sea, yo escuchar eso, yo alucino. [...] Entonces tú dices esos gastos, que... lo que ha pasado en Gamonal o lo que sea, pues yo alucino, que todavía haya ayuntamientos que estén derrochando el dinero" (RG4-EmpleadosMedios). Esa relativa politización que se ha trasladado también a los discursos, consigue que la posición habitualmente hegemónica (en las fracciones centrales de las clases medias y altas) sobre la ineficiencia de lo público, pueda ser discutida y contestada dentro de la dinámica de los grupos:

“-Si es que...Yo creo que el problema es que lo público está mal gestionado. Porque el otro día por ejemplo no sé en donde salió que una cama en un hospital en una clínica privada cuesta ciento cincuenta euros, sin embargo en lo público cuesta cuatrocientos euros. A ver ahí, hay algo que no funciona, el que está gestionando eso... hay un desfase ahí que no tiene ningún sentido. ¡Vamos!

- Habría que ver esos cuatrocientos euros también si hay diferencias entre la clínica privada y la pública... ¿el número de enfermeras que hay, el trato, la profesionalidad de los profesionales, o sea...? Que es que tendemos a denigrar lo público y es cierto que muchas veces..." (RG4-EmpleadosMedios)

Sin que sea posible negar (por la fuerza y la masiva circulación del discurso) la existencia de una relativa ineficiencia en la gestión de lo público al menos se señala que "hay mala gestión, sí, pero aparte hay esa campaña mala de lo público, que yo creo que en fin... que también corresponde a otros intereses" (RG4-EmpleadosMedios). Es decir, el argumento tecnocrático que habitualmente representaría la posición más desideologizada de las clases medias, está más bien desdibujado. Y el consenso dentro de las posiciones centrales en los grupos de estatus medio no cuestiona la necesidad de mantener el sistema público, pero utiliza argumentos más ligados a la identidad colectiva, a una solidaridad básica de derechos de ciudadanía, que vuelve a situar lo público como parte del patrimonio ciudadano:

"Yo creo que la sociedad sí que quiere que se mantenga lo público. Yo creo que los españoles en general tienen claro, por los años que hemos vivido, por cómo nos han educado, en lo cual que nuestro modelo se basa en lo público y yo creo que la mayoría seguimos teniendo la opinión que es el modelo más o menos positivo. Que habrá cosas que hay privatizar, hay cosas que por supuesto la gestión muchas veces es incorrecta..." (RG4-EmpleadosMedios)

Sin embargo, esta exigencia de mantenimiento y fortalecimiento del sector público se enfrenta a las posiciones defensivas y conscientes de la creciente polarización social, aquellas que reclaman una re-elitización de la enseñanza superior o un recorte global en los derechos universales: "bueno en sanidad y en educación en este país se han hecho unos mamoneos también increíbles con dinero público, ¿no? y también creemos que tenemos derecho a cosas que igual no tenemos derecho" (RG9-Becarios). Los derroches no son sólo los obvios en infraestructuras inútiles y corrupciones de todo tipo, sino también los cometidos por los propios usuarios. Aunque estas menciones ocupan un lugar subordinado en los discursos, aparecen incluso en el discurso de los jóvenes 
trabajadores más cualificados y más recelosos de la extensión y universalización de los "privilegios". De manera que, de forma paradójica, la exigencia de proteger los servicios públicos fundamentales se confunde con una defensa de la exclusión y la segmentación en la administración de las políticas sociales.

"Ha habido un abuso de los beneficios que proporcionaba el Estado en la época de bonanza, y también la he visto ¿no?, mucha gente que por ahí hacía partes falsos, o los que estaban becados para ir a estudiar a lo mejor la exigencia era, qué sé yo, aprobar el cincuenta por ciento de las materias y ya está, ¡eh!, yo qué sé, tenías el paro, trabajabas en negro y cobrabas y viva la vida. Entonces, me parece también un abuso ¿no?, entonces no digo que se quite todo pero tampoco sé dé todo, buscar un punto medio.” (RG8-JóvenesHostelería)

Esta relativa proyección de la culpa por los abusos de los propios ciudadanos cometidos durante los años de bonanza es llevada al extremo por las amas de casa de clase alta. Sólo en este grupo de mujeres de clase acomodada se proyecta el mismo discurso disciplinario sobre la irracionalidad en el gasto privado entre las clases populares (que ha tirado de la visa, se ha endeudado, etc.), hacia el consumo que realizan de los servicios públicos. Aunque defiendan a los profesionales (tanto de la enseñanza como del sistema sanitario), sí señalan que nos hemos acostumbrado mal y que deberíamos ser más conscientes de lo que cuestan realmente las cosas para hacer un buen uso de ellas:

“-Nos hemos acostumbrado en este país al gratis total.

$-i$ Es que gratis no es! Gratis no es.

-Hombre, de todas formas es que también había mucho abuso. Había mucho abuso con la seguridad social.

-Si yo me voy 80 veces a que me vea el médico, como entretenimiento, casi. No sé...

-Es que tenemos que tener conciencia de lo que estamos pagando." (RG2-AmasdeCasaAlta)

No son el único grupo que considera necesario que al usuario de un servicio público se le presente el precio real de lo que está utilizando, pero sí el que manifiesta las posiciones más drásticas en favor del recorte del gasto público y de la idea de que "nos han acostumbrado a la subvención." (RG2-AmasdeCasaAlta). Pero incluso los discursos más ofensivos en favor de una racionalización del gasto público critican que los principales recortes tengan lugar en los servicios esenciales existiendo muchas otras opciones para sanear las cuentas públicas. En general, resulta llamativo que en todos los grupos impera un fuerte orgullo por determinados servicios públicos, en particular por el sistema sanitario y sus profesionales, ya que tal y como señalan los empleados entrevistados en Zaragoza "Estados Unidos miraba nuestro sistema de sanidad pública, es que era de los mejores sistemas de sanidad pública que había en el mundo, y actualmente se está llevando a lo que dices tú a manos privadas" (RG4EmpleadosMedios). En el discurso de los empresarios malagueños, los criterios que 
siguen los recortes están absolutamente pervertidos por las corruptelas y los intereses particulares. Aunque representan el otro grupo donde de forma hegemónica se defiende una drástica reducción del gasto estatal, se muestran igualmente críticos con la lógica que están siguiendo unos recortes orientados al gasto social: "yo creo que justamente están recortando, al revés, están recortando en profesores, médicos, enfermeras, no sé qué. Y realmente, donde deben recortar que son en los institutos privados que hay, las empresas públicas, que son privadas. Y ahí es donde realmente, un poco lo que decía $\mathrm{X}$, porque yo creo que ahí es donde están colocados los amigos, los compañeros de partido, los compañeros de sindicato..." (RG1-EmpConstrucción).

Una segunda polarización contrapone el pesimismo hacia el futuro, donde tiende a darse por sentado una creciente privatización de los servicios y minimización del Estado, frente a la sensación de que la degradación en las prestaciones sociales y la atención en los servicios públicos estarían llegando a un límite por debajo del cual la ciudadanía va a ofrecer resistencia.

En otros trabajos (Alonso et al. 2011), ya hemos tratado de analizar las debilidades históricas que arrastra la identificación con lo público en nuestro país, debido al lastre que en el imaginario colectivo ha generado el escaso o nulo papel redistributivo que ha desempeñado el Estado. Una idea que incluso los grupos de jóvenes parecen tener perfectamente integrada, según la cual "en nuestra cultura es casi ofensivo tener que pagar impuestos porque sabemos que ese dinero no nos va a repercutir" (RG8JóvenesHostelería). Por ello, no es de extrañar que al ser interpelado sobre el futuro de los servicios públicos la primera reacción sea muy pesimista o incluso alarmista en prácticamente todos los grupos. Son los propios funcionarios los primeros en considerar que la tendencia hacia una creciente privatización es imparable pues ya "ha ganado la idea de que lo público no funciona, ese es el problema" (RG5-Funcionarios). El desgaste de años de crítica hacia la ineficiencia del funcionario ha conseguido imponer la resignación en el discurso de quienes, en otros momentos de la dinámica, se muestran como firmes defensores de la gestión pública.

"El modelo que viene, el que vamos a empezar a vivir es eso, jeh! El modelo público no va a atender, el que tenga dinero se tendrá que ir a la privada y en la privada te van a atender, pues, pues lo de todos los días, ¿no? Tampoco van a hacer grandes cosas. Y ahí vamos a quedar pues eso, los jubilaos, la gente... los inmigrantes, los no sé qué, esos residuos que ahí se quedan y luego lo demás te lo cogerán y te lo sacarán fuera, porque yo no puedo estar un año con el menisco roto, me voy a gastarme la pe... o pido un crédito y me voy a..." (RG5-Funcionarios)

Pero ellos mismos son quienes mejor conocen los efectos que tiene la privatización de un servicio público, el deterioro en la prestación de los servicios que tiene lugar por el empeoramiento de las condiciones de trabajo y la necesidad de mantener un margen de beneficio. En este sentido, pese a haber sido muy autocríticos con la escasa productividad 
de una parte del funcionariado — en momentos previos de la dinámica—, son también muy críticos con las consecuencias de cualquier proceso de privatización: "Ahí hay un margen que se lo va a llevar siempre la empresa. O sea, ese fundamento es maligno, o sea, nadie hace duros a cuatro pesetas, nadie. El que se queda con la cocina del Hospital lo que va a hacer es dar peor de comer y estrujar a los trabajadores, porque él tiene que tener un beneficio que es mucho mayor que lo que dice. Eso es que es evidente, vamos, dos y dos cuatro, no hace falta tampoco pensar mucho." (RG5-Funcionarios). La posición más radical y afín a la reducción del papel del Estado la representan, como ya hemos señalado, las amas de casa de nuestra RG2-AmasdeCasaAlta. Para ellas, aunque debería mantenerse para los que "de verdad lo necesitan" puesto que "si no sería terrible, sería una sociedad espantosa", la tendencia es una reducción paulatina de la presencia del Estado: "Yo creo que Papá Estado, para un futuro, Papá Estado ya no va a existir" (RG2-AmasdeCasaAlta).

El discurso dominante en el grupo de empresarios de la construcción es lógicamente donde más se subrayan las ineficiencias burocráticas y de gestión dentro del sector público. En este grupo es donde mejor siguen circulando los tópicos (en el contexto actual muy secundarios en el resto de los grupos) sobre el tamaño de la administración, las duplicidades, incluso poniéndose en circulación exageraciones de todo tipo como la idea "de que el ratio de funcionarios por habitante es de no sé si 8 veces que en países como Alemania, tal. Eso es para planteárselo" (RG1-EmpConstrucción). Por ello reproducen el relato de la polarización social asumiendo su traducción en unos servicios públicos cada vez más elitistas: "O sea, está más o menos claro, se está privatizando la... Se está privatizando la sanidad, se va a terminar privatizando la educación, las universidades [...] Es decir, yo entiendo que un escenario muy posible, muy probable, de España, dentro de 20,30 años es que se privaticen todos esos servicios, las oportunidades, la igualdad de oportunidades, se reduzca bastante ¿eh?” (RG1-EmpConstrucción).

Sin embargo, ese aparente pesimismo que comparten las mayorías centrales de todos los grupos, choca con la conciencia de que tras los recortes no hay tan sólo una cuestión de eficiencia, de acabar con los abusos, etc., si no que hay una cuestión de voluntad política. Es decir, por una parte se acepta la necesidad del recorte y se integra el argumento sobre la ineficiencia y el despilfarro en el gasto público. Pero, simultáneamente, se señala cómo hay un punto a partir del cual la continuidad con la política de los recortes implica una elección política por un modelo de sociedad determinada:

"Yo creo que el tema de los recortes no solo depende de eso, si tú tienes una visión de que decides que tienes sanidad pública, tienes sanidad pública hay otros países que no la tiene, pues aquí tienes sanidad pública, pues es una decisión que se toma. No tienes porque te digan no... no tengas sanidad pública, porque tal... no tienes por qué hacer las cosas. Sí al final todos tiene eso globalizado y la Unión Europea y todos tendrán que decir, lo que tengan que decir y al final pues como dice él. Pues yo no pago la deuda, pues yo no hago los recortes y punto pelota y a ver cómo salimos de esta, pues ya se saldrá o no. Pero los recortes no van a ningún lado, no mejoran nada, no..." (RG4-EmpleadosMedios). 
Como discurso más apegado a lo material y a la inmediatez, la posición de las amas de casa de Sevilla es la que describe con mayor libertad la irracionalidad que esconden los recortes situándolos en el contexto de desigualdad y desequilibrio social. Por una parte por el absurdo destino de los recursos, los bancos: "Y ahora tú vas y rescatas a los bancos ¿Para qué? Para que le dé préstamos a las familias que lo necesitan ¿no? Bueno ¿y qué familias? ¿A qué familia se lo vas a dar? Si las familias están viniendo a por una ayuda y ahora un préstamo se lo vas a negar. Por toda la cara. ¿A quién? ¿Quién te va a conceder el préstamo del banco? ¿A quién? ¿A una familia donde entre una ayuda familiar o dos?" (RG6-AmasdeCasaBaja). Por otra parte, porque pese a todo nadamos en la abundancia, la riqueza para ser distribuida es enorme. Simplemente el desequilibrio es irracional, es inexplicable, es pura perversión porque con el dinero de unos poquitos se podría arreglar prácticamente todo:

"Pero es que hay mucha gente con mucho dinero. Y que no son del gobierno sólo ¿eh? Porque todos los casos de corrupción no son sólo del gobierno. Están propiciados por, pero los empresarios del ladrillo no son del gobierno. Y tienen muuucho dinero. ¡Mucho dinero! Es que el tío más rico del mundo podría pagar el alimento para todos los pobres que no tienen dónde comer. Con su dinero. Y la riqueza está, pero centrada en... Y no sólo es el gobierno.” (RG6-AmasdeCasaBaja)

Sin embargo, aunque desde posiciones más abstractas, en casi todos los grupos los participantes expresaban en algún momento de las dinámicas que existe actualmente una situación social explosiva, lo que justifica en buena medida las movilizaciones.

"ahora nos están diciendo que estamos saliendo también porque tenemos que ser un poco más optimistas. Porque la gente está hundida en la miseria." (RG3-PeqPropRurales)

"menos becas para libros, menos para becas de comedor escolar. Sin embargo luego ves que te hacen un aeropuerto en no sé dónde... que no lo han usado en la vida." (RG4-EmpleadosMedios)

"es que estamos llegando a un nivel, que esto está pidiendo una revolución, por la falta de respeto que nos tienen por la gente que nos administra. No puedo decir todos. Pero por lo menos los primeros espadas, que son los que tienen que dar ejemplo, están todos salpicados. Si es que esto es vergonzoso. Es que hemos vivido en la inopia." (RG7-TrabGrandesEmpresas)

Los estudiantes de Barcelona recogen una creciente politización del ambiente juvenil, una incorporación de inquietudes y denuncias políticas en las redes sociales y en las conversaciones cotidianas. Todos los participantes parecen sumarse a la idea de que en sus círculos muchas personas antes completamente desinteresadas y ajenas a lo político están ahora mostrando un cierto interés. Y anticipan en gran medida el ambiente en el que ha tenido lugar las últimas elecciones locales pues "esto tiene que cristalizar de algún modo; - Ya se verá cuando lleguen las elecciones a ver qué pasa" (RG9-Becarios).

Resulta también significativo cómo en la dinámica del grupo de trabajadores de las administraciones públicas circula una autoexigencia de mayor implicación. El grupo 
recoge la idea del poder que pueden llegar a tener los funcionarios medios y bajos por tener acceso a determinada información que pueden hacer pública para denunciar situaciones de abuso o de derroche de recursos. Aunque casos y situaciones concretas vividas o conocidas por los participantes introducen un cierto escepticismo sobre la receptividad de los partidos políticos a esas denuncias, lo cierto es que supone también la exigencia de una mayor implicación:

“-Si, eso, claro. Y los políticos son los que deberían dar ejemplo y están más interesaus en todo lo que puedas filtrar, en todo...

-Mira, nosotros tenemos mucha más capacidad de lo que nos creemos.

-Hay de todo, ;eh! Hay gente muy implicada y que están muy abiertos y muy colaboradores y que enseguida reaccionan y otros que no, que se prestan un poco a decir: A ver si pillo algo, ¿no? Entonces...

-Si, pero aunque no llegues más que a la punta del iceberg, hay cosas que son evidentes, hay partidas que son públicas, hay información que está ahí, entonces, por lo menos todo eso sí se puede sacar." (RG5-Funcionarios)

Pese a la existencia de un apoyo tácito a las movilizaciones contra los recortes, únicamente en los grupos donde hay algún participante que ha estado implicado en ellas, el tema llega a generar un cierto discurso dentro de los grupos (en particular en los tres grupos de perfil más joven). Efectivamente la necesidad de las movilizaciones no es cuestionada por las posiciones dominantes en los grupos pero sí se ponen en cuestión tanto su utilidad — sus efectos concretos- como la necesidad o no de ejercer la violencia.

"Es lo que a mí me preocupa, que las movilizaciones sociales lleguen a un punto de crispación social y que se vea que con la violencia se pueda conseguir, según qué cosas, yo es lo que más me preocupa, es eso" [...]

"¿Qué es más violento, ver a seis millones de personas sin poder llegar que comer o ver un contenedor quemando? Es una pregunta abierta ¿A ver qué es más violento?" (RG4-EmpleadosMedios).

Pero al margen de los tópicos en torno a las movilizaciones, que los grupos no están en situación de trascender (el agotamiento, que cada uno va a lo suyo, que no se les escucha, que vamos los cuatro a los mismos sitios, etc.), varios grupos expresan ya de forma tácita o explícita el deseo de que tanta energía expresada o reprimida pueda salir en las próximas elecciones generales. Posición desligada completamente de una implicación activa, pero receptiva a discursos rupturistas, transcendiendo la idea de una mera sustitución de la elite gobernante que reproduzca la misma estructura:

“-O sea, tú tienes que quitar una oligarquía que está gobernando. Hay que desbancarla porque son unos inútiles.

-Ni todos son inútiles, ni todos son mangantes. Habría que depurar, una depuración, no digo a los tanques, que suena muy duro. Una depuración en el buen sentido de la palabra." (RG7-TrabGrandesEmpresas) 
Frente a la circulación más o menos abierta y aceptada de estos argumentos en varios grupos, el discurso más conservador — presente especialmente en las dinámicas de nuestros grupos RG1-EmpConstrucción y RG2-AmasdeCasaAlta - exige a su manera una movilización pero basada en la lógica del sacrificio $^{11}$, de la entrega, de la unidad de intereses de la nación. Más allá de las movilizaciones lo que echan de menos es una lógica orgánica en el funcionamiento del Estado y la defensa de los intereses de la patria, donde el papel creador de riqueza del empresario vuelva a recuperar su prestigio. Asumen necesariamente la retórica de la regeneración política, de la misma forma que consideran como inevitable la protesta social y el descontento. Es responsabilidad de los políticos asumir su propio sacrificio si fuera necesario, tomando medidas que van a ser contestadas e incomprendidas:

"Zapatero parece que tomó, en marzo de 2010, en mayo, una medida que dice que le costó el puesto, porque redujo salarios, una reforma laboral y tal. Coño, pues harán falta más medidas de esas. Mire usted, probablemente me va a costar, pero ahora mismo tengo que hacer esto.” (RG1-EmpConstrucción)

\section{Conclusión}

La crisis que venimos conociendo desde hace más de un lustro se ha demostrado como un auténtico fenómeno de recomposición tanto de la economía como de las relaciones sociales y por ello de los procesos de producción del sentido y las representaciones colectivas. En esta situación, se despliega una pugna por el control de los recursos, reales y simbólicos que los diferentes grupos sociales presentes en el campo social poseen y tratan de mantener. Esto genera de una manera compleja un sistema de discursos y relatos, resultado de un conflicto social más profundo, que visibilizan en el ámbito de los simbólico las relaciones de dominación realmente existentes en la sociedad. El objetivo de este artículo ha sido vincular las percepciones sociales de la crisis con este marco social de conflicto simbólico constituido en torno al control social de los recursos y el papel de la responsabilidad de los diferentes actores sociales en la generación y gestión de la crisis, partiendo de un trabajo de campo realizado en 2014 sobre el impacto de la crisis en el consumo, con la idea de compararlo con un trabajo previo de 2010. Se realizaron nueve reuniones de grupo en siete ciudades españolas, tratando de recoger diferentes condiciones sociales en términos de ingresos, cualificación y trayectorias de clase probables.

La crisis económica actual ha venido siendo explicada habitualmente, bajo la perspectiva de una economía del comportamiento de matriz neoconductista, como el resultado de los malos cálculos de la población en su conjunto (espíritus animales, euforia, pánico, irracionalidad previsible, etc.), pero frente a esta visión, en los grupos

${ }^{11}$ No vamos a entrar aquí en la importancia de los discursos sacrificiales en los procesos de recorte de los derechos sociales y de uso disciplinario de los programas de austeridad pública porque ya han sido objeto de otros trabajos de este equipo, véase, por ejemplo, Alonso y Fernández Rodríguez (2013b). 
de nuestra investigación aparecen fundamentalmente representaciones colectivas y discursos que le atribuyen a sujetos sociales bien delimitados (políticos, especuladores inmobiliarios y agentes financieros) la responsabilidad de la crisis, percibiendo además que en situaciones buscan la oportunidad de apropiarse de los recursos de otros. Incluso en los discursos políticamente más activos se llega a argumentar que los poderes financieros han emprendido una cruzada para apropiarse de recursos que antes eran públicos o para recomponer las relaciones entre capital y trabajo construidas en el período fordista, alterando las condiciones vitales de las clases medias y populares de la España del siglo XXI.

En la evolución de la crisis se han ido haciendo hueco explicaciones y relatos que han resquebrajado el discurso autodisciplinario dominante que se construía como espejo mimético del difundido por los agentes financieros -y por sus representantes en la política institucional-, y que responsabilizaban de la crisis a aquellos que no podían hacer frente a las deudas contraídas o que contribuían al surgimiento de esa deuda en forma de gasto público; aquí los chivos expiatorios han sido diversos: los desahuciados, los inmigrantes endeudados en exceso, Grecia, los españoles que han vivido por encima de sus posibilidades, los trabajadores del sector público, los dependientes, los parados, que no quieren trabajar, los jubilados, etc. Sin embargo, este relato típico del diagnóstico conservador de la crisis -el de la culpabilidad popular por cualquiera de sus vías- aunque se mantiene ha ido perdiendo adeptos y ha ganado un muy importante espacio discursivo la idea fuerza de que el conjunto de poderes dominantes considerados de una manera indiferenciada -de ahí el existo posterior del concepto de casta-, acumulan sin freno por desposesión del resto de la población.

Se reconoce así un enorme desgaste y desvitalización del discurso de que la única posibilidad para encontrar una salida de la crisis es aceptar las políticas diseñadas por parte de las élites dominantes, dejándolas constituirse como cirujano de hierro que toma las decisiones más duras e implacables (reformas en el mercado de trabajo, recorte en el gasto público, austeridad radical en los servicios sociales, máxima facilidad, seguridad y rentabilidad para los inversores, etc.), discurso que se desplegó como auténtico dispositivo disciplinario a comienzos de la crisis con fuertes dosis de consenso y legitimación entre gran parte de las clases medias españolas, tal como habíamos mostrado en varios de nuestros trabajo anteriores. Por el contrario en este segundo momento de la investigación el discurso de la crisis se percibe como el recurso de los poderosos -y fundamentalmente los políticos- para ocultar su incompetencia, sus corruptelas y sus irracionalidades.

Frente a la idea de la recuperación económica inmediata, en los grupos existía ya un consenso generalizado en que el país está inmerso en una crisis muy profunda, que todo el mundo se ha visto obligado a ajustar sus presupuestos, y que hemos experimentado no tanto una crisis del consumo como un consumo de crisis adaptado a estas nuevas expectativas limitadas. Los participantes de los grupos, con independencia de su origen social, mencionan que gastan menos (sobre todo en ocio, pero no exclusivamente) y describen distintas estrategias de ahorro, mencionándose a los hijos y jóvenes como fuente fundamental de incertidumbre (que toma la forma abierta de miedo en muchas ocasiones), estando presente, como realidad inmediata o como temido fantasma 
omnipresente, el desclasamiento y la pérdida absoluta o relativa de estatus y nivel social. Relacionado con esto, aparecen los efectos que la crisis económica está generando, de manera directa e indirecta, en las formas de consumo y sus prácticas, y aquí las posiciones son contradictoras y los participantes mantienen diferentes visiones acerca de cómo será el consumo en un escenario post-crisis, desde los más alternativos que argumentan que la crisis cambiará para siempre las percepciones de la ciudadanía en relación al consumo a los más convencionales que, por el contrario, señalan que tan pronto la economía se recupere mínimamente, la gente retornará al consumismo.

Lo que sí se quiebra significativamente es el tópico discursivo de que los españoles habían estado viviendo por encima de sus posibilidades (tanto por los servicios públicos disponibles como por el nivel de consumo alcanzado). Esta era una idea que había aparecido con toda su eficacia ideológica en la investigación de 2010, y queríamos comprobar si todavía constituía un discurso hegemónico. Algunos grupos, como el de empresarios del sector de la construcción todavía defienden en 2014 este diagnóstico con vehemencia; pero en otros grupos, esta idea es ya rechazada de plano, particularmente entre las amas de casa de clase baja y los trabajadores industriales mayores. En el resto de los grupos su eficacia se ha desdibujado claramente. También, por comparación con lo que ocurría en 2010, podemos concluir que hay más acuerdo en señalar a la clase política como la culpable del declive económico y social del país, lo que limita drásticamente los efectos del discurso autoculpabilizador que tan eficazmente se extendió en los primeros años de la crisis. Prácticamente todos los participantes, con independencia de su clase social y de si han sido directamente golpeados por la crisis, reconocen haber ajustado su presupuesto y estilo de vida. Existe también división de opiniones respecto a si este cambio tiene un carácter estructural o es meramente un resultado de la negativa coyuntura económica. Pero más allá de las ambivalencias enunciativas de las clases medias representadas (preconservadoras en unos contextos, prerradicales en otros) un discurso mucho más crítico con la idea del "hemos vivido por encima de nuestras posibilidades" ha tomado cuerpo en la sociedad española, pese a que la idea todavía mantenga fuerza residual en los sectores más conservadores, y se culpa a la clase política de la gestión catastrófica del país y del empobrecimiento de la ciudadanía. La explicación sacrificial de la crisis construida por las élites ha terminado, poco a poco, entrando a su vez en crisis.

\section{Bibliografía}

Alonso, L. E. (1998): La mirada cualitativa en sociología, Madrid, Fundamentos.

Alonso, L. E. (2007): La crisis de la ciudadanía laboral, Barcelona, Anthropos.

Alonso, L. E. (2013): "La sociohermenéutica como programa de investigación en sociología", Arbor. Ciencia, pensamiento y cultura, 761 (189), a035, doi: 10.3989/ arbor.2013.761n3003

Alonso L. E. y C.J. Fernández Rodríguez (2013a): Los discursos del presente, Madrid, Siglo XXI. 
Alonso, L, E. y C. J. Fernández Rodríguez (2013b): "Debemos aplacar a los mercados: el espacio del sacrificio en la crisis financiera actual", Vínculos de Historia, 2, pp. 97-119.

Alonso, L. E., , C. J. Fernández Rodríguez y R. Ibáñez Rojo (2011): "Del consumismo a la culpabilidad: en torno a los efectos disciplinarios de la crisis económica", Política y Sociedad, 48 (2), pp. 353-379, doi: 10.5209/rev_POSO.2011.v48.n2.8

Alonso, L. E., C.J. Fernández Rodríguez y R. Ibáñez Rojo (2012): "Las identidades de ocio y consumo de los jóvenes en la era postlaboral", en Tezanos, J. F. (ed.), Los nuevos problemas sociales: Duodécimo Foro sobre tendencias sociales, pp. 453479.

Alonso, L. E., C.J. Fernández Rodríguez y R. Ibáñez Rojo, R. (2015): "From consumerism to guilt: economic crisis and discourses about consumption in Spain", Journal of Consumer Culture, 15(1), pp. 66-85, doi: 10.1177/1469540513493203

Bajtin, M. (1978): La cultura popular en la Edad media y el Renacimiento, Madrid, Alianza.

Bauman, Z. (2011): Daños colaterales, Madrid y México, Fondo de Cultura Económica.

Callejo, J. (2001): El grupo de discusión: introducción a una práctica de investigación, Barcelona, Ariel.

Chavel, L. (2006) : Les classes moyennes à la derive, París, Seuil.

Cingolani, P. (2015): La précarité, París, Presses Universitaires de France.

Conde Gutiérrez del Álamo, F. (2009): Análisis sociológico del sistema de discursos, Madrid, CIS.

Cowen, T. (2014): Se acabó la clase media, Barcelona, Antoni Bosch Editor.

Damon, J. (2013): Les classes moyennes, París, Presses Universitaires de France.

Eagleton, T. (2001): La idea de cultura. Una mirada política sobre los conflictos culturales, Barcelona, Paidós.

Gaggi, M. y E. Narduzzi (2006): El fin de la clase media, Madrid, Lengua de Trapo.

Hernández, E. (2014): El fin de la clase media, Madrid, Clave Intelectual.

Lanchester, J. (2014): “On Capital”, New Statesman, 5 marzo, suplemento

Martín Criado, E. (1997): "El grupo de discusión como situación social”, Revista Española de Investigaciones Sociológicas, 79, pp. 81-112.

Maurin, E. (2009): La peur du déclasemment, París, Seuil.

Ortí, A. (1986): "La apertura y el enfoque cualitativo o estructural: la entrevista abierta o semidirecta y la discusión de grupo", en García Ferrando, M., J. Ibáñez y F. Alvira (comps.), El análisis de la realidad social. Métodos y técnicas de investigación, Madrid, Alianza, pp. 171-203.

Paugam, S. (2007): Le salarié de la précarité, París, Presses Universitaires de France.

Peugny, C. (2009): Le déclassement, París, Grasset.

Revelli, M. (2015): La lucha de clases existe ... iy la han ganado los ricos!, Madrid, Alianza.

Ricoeur, P. (2003): El conflicto de las interpretaciones, México y Buenos Aires, Fondo de Cultura Económica.

Sassen S. (2015): Expulsiones. Brutalidad y complejidad en la economía global, Buenos Aires, Katz. 
Standing, G. (2013): El precariado. Una nueva clase social, Barcelona, Pasado y Presente.

Standing, G. (2014): Precariado. Una carta de derechos, Madrid, Capitán Swing.

Taibbi, M. (2015): La brecha, Madrid, Capitán Swing.

Therborn, G. (1987): La ideología del poder y el poder de la ideología, Madrid, Siglo XXI.

Voloshinov, V.N. (1976): El signo ideológico y la filosofía del lenguaje, Buenos Aires, Nueva Visión. 